\title{
The Use of Weather Research and Forecasting Model to Predict Rainfall in Tropical Peatland: 1. Model Parameterization
}

\author{
Alfi Rizky Sanusi, Muh Taufik, I Putu Santikayasa \\ Department of Geophysics and Meteorology, Faculty of Mathematics and Natural Sciences, IPB University, Dramaga Campus, \\ Bogor, Indonesia 16680
}

\section{ARTICLE INFO}

\section{Received}

12 April 2021

\section{Revised}

1 June 2021

\section{Accepted for Publication}

7 June 2021

\section{Published}

30 June 2021

doi: 10.29244/j.agromet.35.1.49-59

\section{Correspondence: \\ Muh Taufik \\ Department of Geophysics and Meteorology, Faculty of Mathematics and Natural Sciences, IPB University, Dramaga Campus, Bogor, Indonesia 16680 \\ Email: mtaufik@apps.ipb.ac.id}

\section{This is an open-access article} distributed under the CC BY License. (c) 2021 The Authors. Agromet.

\begin{abstract}
A B S T R A C T
Rainfall dynamics play a vital role in tropical peatland by providing sufficient water to keep peat moist throughout the year. Therefore, information of rainfall data either historical or forecasting data has risen in recent decades especially for an alert system of fire. Here the Weather and Research Forecasting (WRF) model may act as a tool to provide forecasting weather data. This study aims to do parameterization on WRF parameters for peatland in Sumatra, and to perform bias correction on the WRF's rainfall output with observed data. We performed stepwise calibration to choose the best five physical schemes of WRF for use in the study area. The output WRF's rainfall was bias corrected by spatially observed rainfall data for 2019 at day resolution. Our results showed the following schemes namely (i) Eta scheme for cloud microphysical parameters; (ii) GD scheme for cumulus cloud parameters, (iii) MYJ scheme for planetary boundary layer parameters; (iv) RRTM for longwave radiation; and (v) New Goddard schemes for shortwave radiation are best combination for being used to predict rainfall in maritime continent. The spatially interpolated observed rainfall with the Inverse Distance Weighting (IDW) was outperformed for calibration process of WRF's rainfall as shown by statistical indicators used in this study. Further, the findings have contributed to advance knowledge of rainfall forecasting in maritime continent, particularly in providing data to support the development of fire danger rating system for Indonesian peatland.
\end{abstract}

\section{KEYWORDS}

bias correction, gamma quantile mapping, Inverse Distance Weighting,

Polygon Thiessen, stepwise calibration

\section{INTRODUCTION}

Information on weather forecast has an important role in daily life and human activities, planning for infrastructure development, aviation, shipping, or other daily work activities. The weather variable that most concerned is rainfall because it typically has a high variability and it affects many sectors of human activities. Prolonged rainfall may lead to flood events (Ciric et al., 2017; Suciantini and Hidayat, 2006; Surmaini et al., 2018), while the absent of rainfall for a long period will trigger drought associated wildfire in humid tropics (Taufik, 2010; Taufik et al., 2019).
Understanding tropical rainfall characteristics remains research challenge (Tan et al., 2019) especially when deal with rainfall forecasting at daily resolution.

There have been many approaches and methods that have been developed in recent decades to generate rainfall data. The most widely used methods are statistical based model and dynamic model. For statistical models, Markov chains and Fourier regression (Liu et al., 2020; D. Wang et al., 2020) were widely applied to generate rainfall data. On the other hand, Weather Research and Forecasting (WRF) model represents the dynamic one, which takes into account 
various meteorological factors that can affect weather conditions (Powers et al., 2017; Yáñez-Morroni et al., 2018). Regardless of the methods used, results of the rainfall generation and prediction, which represent actual measurement are more important as its high variability both on spatial and temporal scales. Therefore, improvement on the model prediction is necessary to obtain more accurate prediction results.

In this research, we used the Weather and Research Forecasting (WRF) model for its application in tropical peatland. Fires are common phenomena during dry season in Indonesian peatlands (Taufik et al., 2019, 2017), which has severe ecological and economic impacts (World Bank, 2016). This has raised society awareness on how to deal with recurrent fire events. For instance through development of forest fire danger rating systems (e.g. Sankey, 2018). The systems will provide an alert of fire danger level on daily basis; therefore, fire impacts will be reduced. However, information on future level of fire danger remains research concerns as it needs more data of weather forecasting onward. Here, WRF will play an important role to provide forecasting weather data until 16 days ahead.

The use of WRF needs model parameterization to adapt local factors such as topography, land-use and climate. The parameterization emphasizes on the five model schemes of WRF namely Microphysical of cloud, Cumulus cloud, Planetary boundary layer, Long(Taufik, 2010)wave and Shortwave radiation. Also, calibration process of the WRF products with observed data is still needed to obtain good results. In this research, we used WRF model to provide daily rainfall data for peatland region in Sumatra. The research area of interest includes peatlands in Riau, Jambi, and South Sumatera. The objective of this research are as follows: to do model parameterization for obtaining the most suitable WRF physical scheme for tropical regions, especially the Sumatra, and to perform a bias correction of WRF output with observation data.

\section{RESEARCH METHODS}

The process of obtaining forecasting weather data is started with the installation of the WRF Preprocessing System (WPS) and WRF program application. Several supported libraries that enable in the process of reading and processing several data formats, such as NetCDF, MPICH, zlib, libpng, and Jasper were required. These five libraries were used to read Global Forecasting System (GFS) input data and to process it based on specific location and time. WPS is a program application for determining the model domains and interpolating the terrestrial data (Figure 1a).

WPS are equipped with the ability to read geographic location areas, so that an area of interest in this research can be created using the domain concept. Determination of the area (domain) can be made in various resolutions and extents. GFS data that has spatial resolution of $0.5^{\circ} \times 0.5^{\circ}$ was downscaled with WPS as needed, which can be set in the "namelist.wps". In preparation for obtaining the rainfall forecast data, the GFS data was downscaled by two domains through the "geogrid.exe" program. Domain 1 (d01) with a spatial resolution of $15 \mathrm{~km} \times 15 \mathrm{~km}$, and domain 2 (d02) with a spatial resolution of $5 \mathrm{~km} \times 5 \mathrm{~km}$ (Figure 1b).

GFS data was read with "ungrib.exe" program and followed by the "metgrid.exe" program to horizontally interpolate from the extracted data. The output of the WPS model in the form of a met_em* file will be executed with the "real.exe" dan "wrf.exe" programs on the WRF model. In other words, WPS is run to prepare data based on the desire time and location for further prediction of weather parameters based on various scheme in WRF.

After obtaining the met_em* file from the WPS program output, the process then continued to the WRF model. WRF is a model that runs two programs from the WPS model's output, namely "real.exe", which
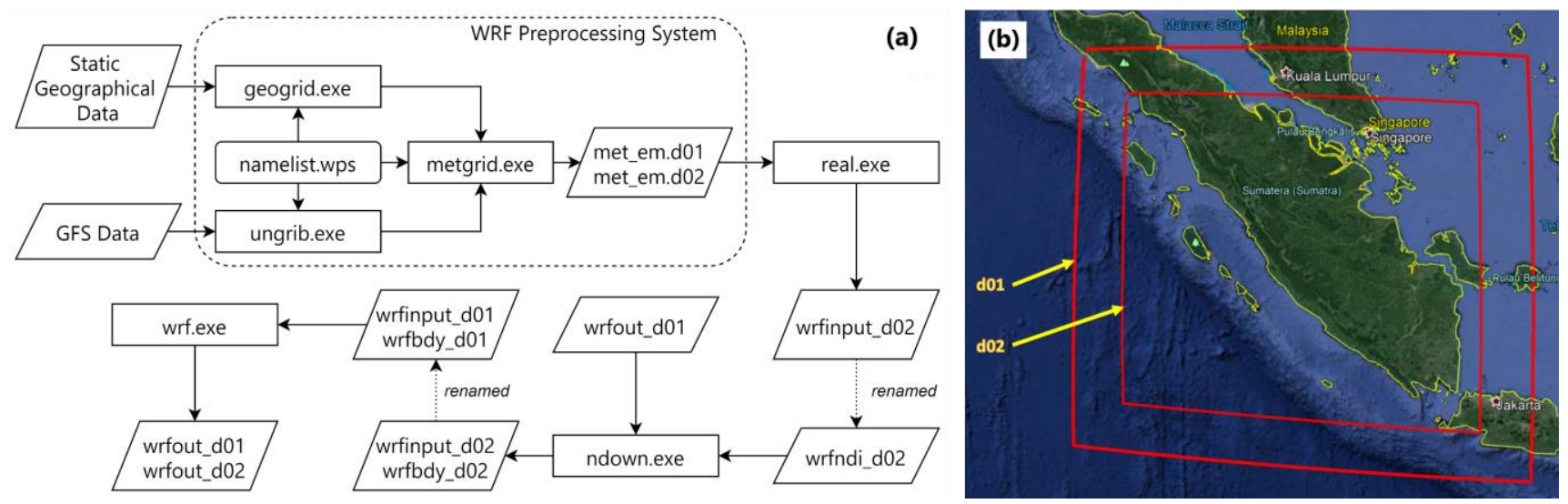

Figure 1. WRF working system: (a) flowchart of the system, which combine two domains (nested); (b) the domains area used in this research. 
shows that the model is running the system from real case data in the atmosphere and the earth's surface with physical weather parameters, and "wrf.exe", which runs the parameter scheme "namelist.input" which is arranged according to the needs of the weather prediction. Figure 1a shows the WRF workflow with two domains (nested) according to the rainfall prediction model concept that is compiled. The output of the WRF model in the form of wrfout_d02 is converted into NetCDF format, which is then processed using $R$ language to obtain rainfall data. The selection of the WRF model parameterization scheme is presented in Table 1. The configuration selection is based on trial and error to obtain the most accurate output for the area of interest in estimating rainfall variables.

\section{Parameterization of the WRF model}

The WRF is a model that performs the function of data processing by integrating various meteorological variables in the earth's surface and atmosphere to run a physically weather model. For each physical parameter of the weather model, there are some of schema options that can be selected by the user to run the WRF. The choice of scheme for each weather parameter will determine the output of the forescating data of WRF. There are five physical parameters of the core weather parameters are used in the WRF model, namely cloud microphysical parameters, cumulus cloud $(\mathrm{Cu})$, planetary boundary layer (PBL), longwave radiation and shortwave radiation. Cloud microphysical parameters, cumulus cloud $(\mathrm{Cu})$, and planetary boundary layer are of primary importance for simulating precipitation and are likely to affect both spatial and temporal variability of the rainfall field (Nuijens and Siebesma, 2019; Zheng et al., 2017). Order than that, longwave and shortwave radiation have a role to explain the albedo and cloud cover. These five physical parameters strongly influence to prediction of WRF model, especially rainfall data (Dai, 2006). The process of parameterization of the WRF physical scheme was carried out by stepwise calibration method for each scheme for each parameter (Table 1).

The parameterization process was carried out by fitting each scheme, which resulted in predicted rainfall data. The predicted data, then, was compared to that of the Climate Hazard Group InfraRed Precipitation with Station (CHIRPS), which acted as spatial observation data. CHIPRS rainfall data was used because it's performance is proven worldwide to represent observed rainfall (e.g. Babaousmail et al., 2019; Chen et al., 2020; Jadmiko et al., 2019; Rivera et al., 2018).

The performance of the physical parameter schemes WRF model was assessed statistically based on the value of the Mean Absolute Error (MAE) statistical indicator. The process was carried out in gradual process (a stepwise calibration) based on sequence of physical parameters in Table 1. If the smallest MAE is obtained from a schematic on cloud microphysical parameters, then the scheme was used in the WRF model to further estimate the cumulus cloud (Cu) parameter. This gradual process was carried out up to the parameterization of shortwave radiation.

Table 1. WRF model parameters and schema variations that used in the model parameterization.

\begin{tabular}{cll}
\hline No & \multicolumn{1}{c}{ Parameter } & \multicolumn{1}{c}{ Scheme } \\
\hline 1 & Microphysical of cloud (mp_physics) & Kessler Scheme \\
\cline { 3 - 3 } & & WRF Single Moment 5-class Scheme \\
\cline { 3 - 3 } & & Eta Scheme \\
\cline { 3 - 3 } & & Thompson Scheme \\
\cline { 3 - 3 } & & Kain-Fritsch Scheme \\
\cline { 3 - 3 } & & Grell-Freitas Ensemble Scheme \\
\hline 3 & Planetary Boundary Layer (bl_pbl_physics) & Grell-Devenyi (GD) Ensemble Scheme \\
\cline { 3 - 3 } & & Yonsei University Scheme (YSU) \\
\cline { 3 - 3 } & & Mellor-Yamada-Janjic Scheme (MYJ) \\
\hline 4 & Longwave radiation (ra_Iw_physics) & RRTM Scheme \\
\cline { 3 - 3 } & & New Goddard Scheme \\
\cline { 3 - 3 } & & Fu-Liou-Gu Scheme (FLG) \\
\hline 5 & Shortwave radiation (ra_sw_physics) & Dudhia Scheme \\
\cline { 3 - 3 } & & Goddard Scheme \\
\cline { 3 - 3 } & & New Goddard Scheme \\
\hline & &
\end{tabular}


The assumption that used is the cloud microphysical parameter is the major parameter in influencing the rainfall variable, and the minor effect (from these five parameters) is given from shortwave radiation (Gunwani et al., 2021). This assumption is based on the results of a few studies showing that the cloud microphysical parameter, cumulus clouds, and planetary boundary layer (PBL) are the main (major) physical parameter factors in the WRF model that affect the output of the WRF model, especially for rainfall data (Mu et al., 2019).

\section{Bias Correction of WRF Rainfall Data}

Rainfall data from WRF model that has been parameterized, still needs to be corrected with field measurement data to complete the process of adjusting the WRF output data to local weather conditions. The rainfall data that used to do the bias correction to the WRF output data are rainfall data from airport stations are located around the area of interest provinces, namely Riau, Jambi, and South Sumatera. The bias correction process uses daily timeseries data for the period January - December 2019. The method for the process of bias correction is gamma quantile mapping that was introduced by Piani et al., (2010). The bias correction towards WRF rainfall data was carried out in spatial method. Field station observation data were interpolated into spatial using the Polygon Thiessen and Inverse Distance Weighting (IDW) methods, then analyzed to get the best method to use as a reference in bias correction.

\section{Polygon Thiessen Method}

Rainfall data from WRF output in the form of matrix data with a spatial resolution of $5 \mathrm{~km} \times 5 \mathrm{~km}$ needs bias correction using field or observation measurement data. Field measurements are carried out at weather observation stations at certain coordinate locations, so that in order to be used as a basis for bias correction to the WRF output, it is necessary to carry out spatial interpolation of rainfall data. One of the methods of spatial interpolation of rainfall data is the Polygon Thiessen method. This method is also known as weighted average, because each rainfall observation station is mapped to determine the coverage area that is considered capable of being represented through data from each rainfall observation station whose area is in the form of a polygon (Figure 2).

\section{Inverse Distance Weighting (IDW) Method}

Another spatial interpolation method that used is IDW, which is a conventional interpolation method that calculates distance as a weight. The meaning of distance in this method is the length of the path from each data point to area that the value will be estimated. Through this simple concept, the closer distance between the points, the greater the weight, and vice versa. The area that is closer to the observation station will be more influenced by the rainfall value that recorded at that station.

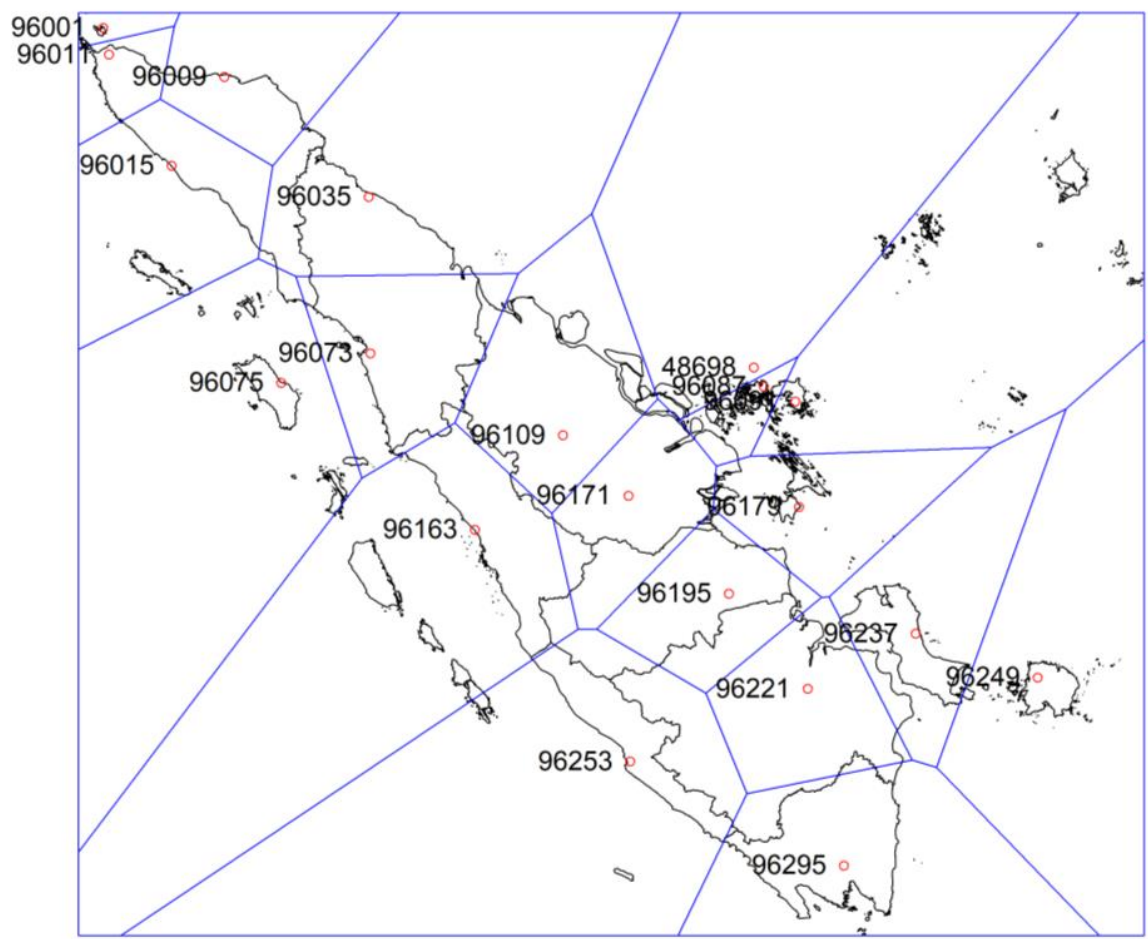

Figure 2. The result of Polygon Thiessen based on the airport weather station around Sumatera Island. Red circle shows the location of each weather station labelled by the WMO ID number. 
The IDW simple concept calculation is shown in Equation 1 (Sun et al., 2019).

$$
Z_{0}=\frac{\sum_{i=1}^{n} Z_{i} \frac{1}{d_{1}{ }^{k}}}{\sum_{i=1}^{n} \frac{1}{d_{1}{ }^{k}}}
$$

where $Z_{0}$ is the estimated value at point $0, Z_{1}$ is the rainfall at the observation station, $d_{1}$ is the distance between the station and the point where the rainfall data is to be known, $\mathrm{k}$ is the distance weight factor (the greater the value of $k$, the greater effect of the rainfall value from the nearest station), and $n$ is the number of station points that used.

\section{Statistical Indicator that Used (Goodness-of-Fit) 1. Mean Absolute Error (MAE)}

The process of parameterization of the WRF model scheme is determined based on the magnitude of the error value generated between the rainfall data from the WRF output and the observed rainfall data. The statistical indicator that used is Mean Absolute Error (MAE) which will show a better accuracy when the value of MAE is closer to 0 . MAE is the average deviation between the model value and the observed value (Equation 2). MAE values that are less than or equal to half the standard deviation of the observed data can indicate that a model is acceptable (Phogat et al., 2016).

$$
M A E=\frac{\sum_{i=1}^{n}\left|y_{i}-x_{i}\right|}{n}
$$

where $y_{i}$ is the output data of the WRF model on day-i, $x_{i}$ is the observation measurement data on day-i, and $n$ is the total length of the data. If in the process of parameterization of the WRF model scheme uses MAE statistical indicators, to evaluate the accuracy and performance of bias correction of the WRF model with observation data is using four statistical indicators, namely Nash-Sutclife Efficiency (NSE), Root Mean Square Error (RMSE), Percent bias (PBIAS), and Pearson correlation (r).

\section{Nash-Sutcliffe Efficiency (NSE)}

The NSE statistical indicator is a statistical method that calculates the relative value and residual variance compared to the variance of observational data (Tegegne et al., 2017). The NSE value ranges from $-\infty$ to 1 . The closer to 1 , the smaller residual value, which means that the model output data is better and more acceptable. The NSE value can be calculated using Equation 3.

$$
N S E=1-\left[\frac{\sum_{i=1}^{n}\left(x_{i}-y_{i}\right)^{2}}{\sum \quad\left(x_{i}-x_{\text {mean }}\right)^{2}}\right]
$$

where $x_{i}$ is the observation data on day- $i, y_{i}$ is the WRF model data on day-i, and $x_{\text {mean }}$ is the average of the observed data.

\section{Root Mean Square Error (RMSE)}

RMSE is a statistical indicator that used to estimate the error value of the data model (Harwell, 2019). The quality and accuracy of the model will be better if the error value is getting smaller which is indicated by the lower RMSE value. RMSE calculation is shown in Equation 4.

$$
R M S E=\sqrt{\sum_{i=1}^{n}\left(x_{i}-y_{i}\right)^{2}}
$$

\section{Percent Bias (PBIAS)}

The PBIAS statistical indicator can be used to calculate the average trend of greater or lesser trends in the model data against the observational data. The less bias between the model and the observational data which is indicated by a PBIAS value that is closer to zero. A positive value on PBIAS indicates an underestimate model, while a negative value in PBIAS indicates an overestimate model towards the observational data (Berhanu et al., 2016). The formula for calculating the PBIAS statistical indicator is shown in Equation 5.

$$
\text { PBIAS }=\left[\frac{\sum_{i=1}^{n}\left(x_{i}-y_{i}\right) \times 100}{\sum_{i=1}^{n} x_{i}}\right]
$$

\section{Pearson Correlation (r)}

Correlation is a statistical indicator that obtained from the linier relationship between the model and the observational data. The positive value of the correlation indicates a unidirectional relationship between the model and the observation data. Vice versa, if the correlation is negative, it indicates a relationship that is not unidirectional or inverse between the model and observational data. The value of the Pearson Correlation is in the range of -1 to 1 . The closer of correlation into 1 or -1 , the correlation or relationship between the model and observations is getting stronger, while the closer to 0 the relationship is getting weaker. The calculation of the Pearson Correlation is shown in Equation 6.

$$
r=\sqrt{1-\left(\frac{\sum_{i=1}^{n}\left(x_{i}-y_{i}\right)^{2}}{\sum_{i=1}^{n}\left(x_{i}-\underline{y}_{i}\right)^{2}}\right)}
$$

\section{RESULTS AND DISCUSSIONS}

The WRF model is a weather prediction model that can able to provide forecast information for the weather parameters for up to 16 days continuously on a global scale. The process in the WRF model uses various schemes in defining each parameter that can affect the weather forecast information. Of course, these various schemes need to be parameterized in order to obtain weather information that is in accordance with the actual conditions in the field. In addition, even though the WRF model has been 
parameterized, each model must have errors and biases. Therefore, the output of the WRF model that has been parameterized needs bias correction.

\section{WRF Model Schematic Parameterization}

The process of a parameterization of the WRF model scheme is carried out using the stepwise calibration method with the assumption that cloud microphysical parameters area the parameters that have the greatest influence on the output of the WRF model, so the process starts from cloud microphysical parameters. Based on the parameterization results of the WRF model scheme carried out with CHIRPS data (Table 2), it can be seen that the rainfall MAE value for each input in the physical parameters varies greatly. In the microphysical cloud parameterization process, the MAE value ranges from $20.75-28.35$ with the lowest MAE value in the Eta scheme, so the Eta scheme is selected I the WRF model configuration as a cloud microphysical parameter to further test the other parameters. Eta microphysical scheme is an efficient scheme with the diagnosis of cloud physical factor mixing process. The Eta scheme is also used in operational models at the National Centre for Environmental Prediction (NCEP). The second parameter is the cumulus cloud which have MAE values ranging from 18.91 - 30.19 after pairing it with the Eta scheme on cloud microphysical parameters. This range of values indicates as increase in the MAE value when the Eta scheme in the cloud microphysical parameters is paired with the Kain - Fritsch sheme in the cumulus cloud parameter. The lowest MAE value is obtained in the Grell - Devenyi (GD) scheme as a cumulus cloud parameter. The GD scheme is known as the ensemble GD scheme, because the scheme uses an ensemble member from 114 sub-grids to obtain a more accurate cumulus cloud parameterization scheme.

The third parameter to be analyzed is Planetary Boundary Layer (PBL). From a total of 13 schemes that available in the WRF model, only three was selected to be used in this parameterization process. The selection of three schemes is based on a few of existing studies which state that three schemes is commonly used and have the best weather prediction concept for PBL parameter. The results of testing the combination of the two parameters that have been selected with each PBL scheme, obtained the lowest MAE in MellorYamada-Janjic (MYJ) scheme. This scheme is uses the concept of Turbulence Kinetic Energy (TKE) as input in PBL parameters.

The combination of three parameters that have been selected for each scheme is used to determine the schematic of longwave and shortwave radiation parameters. For each wavelength, three schemes were selected which were considered to have strong linkages with the needs of weather prediction, especially in tropical regions. The RRTM scheme for longwave radiation parameters and the New Goddard scheme for shortwave radiation parameters reduces the MAE value by almost $50 \%$ (from 15.42 to 7.91 ). This combination is the final result in the process of determining the scheme for the five physical parameters in WRF model.

Table 2. WRF Model Configuration.

\begin{tabular}{|c|c|c|c|}
\hline No & Parameter & Schema & MAE \\
\hline \multirow[t]{4}{*}{1} & \multirow{4}{*}{$\begin{array}{l}\text { Cloud Microphysical } \\
\text { (mp_physics) }\end{array}$} & Kessler Scheme & 25.66 \\
\hline & & WRF Single Moment 5-class Scheme & 28.35 \\
\hline & & Eta Scheme & 20.75 \\
\hline & & Thompson Scheme & 24.86 \\
\hline \multirow[t]{3}{*}{2} & \multirow[t]{3}{*}{ Cumulus Cloud (Cu) } & Kain-Fritsch Scheme & 30.19 \\
\hline & & Grell-Freitas Ensemble Scheme & 20.86 \\
\hline & & Grell-Devenyi (GD) Ensemble Scheme & 18.91 \\
\hline \multirow[t]{3}{*}{3} & \multirow{3}{*}{$\begin{array}{l}\text { Planetary Boundary Layer } \\
\text { (bl_pbl_physics) }\end{array}$} & Yonsei University Scheme (YSU) & 22.17 \\
\hline & & Mellor-Yamada-Janjic Scheme (MYJ) & 15.42 \\
\hline & & NCEP GFS Scheme & 25.23 \\
\hline \multirow[t]{3}{*}{4} & \multirow{3}{*}{$\begin{array}{l}\text { Longwave Radiation } \\
\text { (ra_lw_physics) }\end{array}$} & RRTM Scheme & 11.24 \\
\hline & & New Goddard Scheme & 15.98 \\
\hline & & Fu-Liou-Gu Scheme (FLG) & 19.22 \\
\hline \multirow[t]{3}{*}{5} & \multirow{3}{*}{$\begin{array}{l}\text { Shortwave Radiation } \\
\text { (ra_sw_physics) }\end{array}$} & Dudhia Scheme & 8.64 \\
\hline & & Goddard Scheme & 8.48 \\
\hline & & New Goddard Scheme & 7.91 \\
\hline
\end{tabular}


The Rapid Radiative Transfer Model (RRTM) scheme is an efficient scheme using look-up tables and multiple bands in describing longwave radiation. In addition, the New Goddard scheme is uses multiple bands and ozone for climatological data to represent shortwave radiation.

\section{Bias Correction of WRF's Rainfall Output}

The evaluation of the WRF model output bias correction process was carried out by comparing the corrected rainfall model data with the spatial rainfall observational data. The statistical indicators that used were RMSE, PBIAS, NSE, and Pearson correlation ( $r$ ). Before and after the bias correction process is displayed for each statistical indicator, so it can be seen clearly how different and change in each results of the bias correction process. The bias correction method that used is the daily rainfall bias correction of gamma quantile mapping which is available in the hyfo package in R software (Piani et al., 2010).

\section{Polygon Thiessen Method}

The process of bias correction of rainfall data from WRF output using the Polygon Thiessen method in conducting spatial interpolation of rainfall data from weather station measurements resulted an increasing performance significantly (Figure 3a). The value of the RMSE and PBIAS statistical indicators was significantly reduced, which indicates that the method eliminates errors and bias from the WRF rainfall data very well. The NSE indicator also shows that the bias correctios process using the Polygon Thiessen method has succeeded in deliver rainfall data have a good efficiency. For the Pearson correlation indicator ( $r$ ), it doesn't show a big change from before and after the bias correction process.

\section{IDW Method}

Bias correction of the output rainfall data from the WRF model using the IDW method in the spatial interpolation process of station observational data has statistical indicators that tend to be similar to the Polygon Thiessen method (Figure 3b). The bias correction process using the IDW method has succeeded in reducing the error and bias values significantly and the efficiency is getting better. But, likewise the Polygon Thiessen method, the Pearson correlation statistical indicator didn't differ much between before and after the bias correction process. Therefore, in order to see the performance comparison between the Polygon Thiessen and IDW methods, the analysis was continued by comparing the two methods.
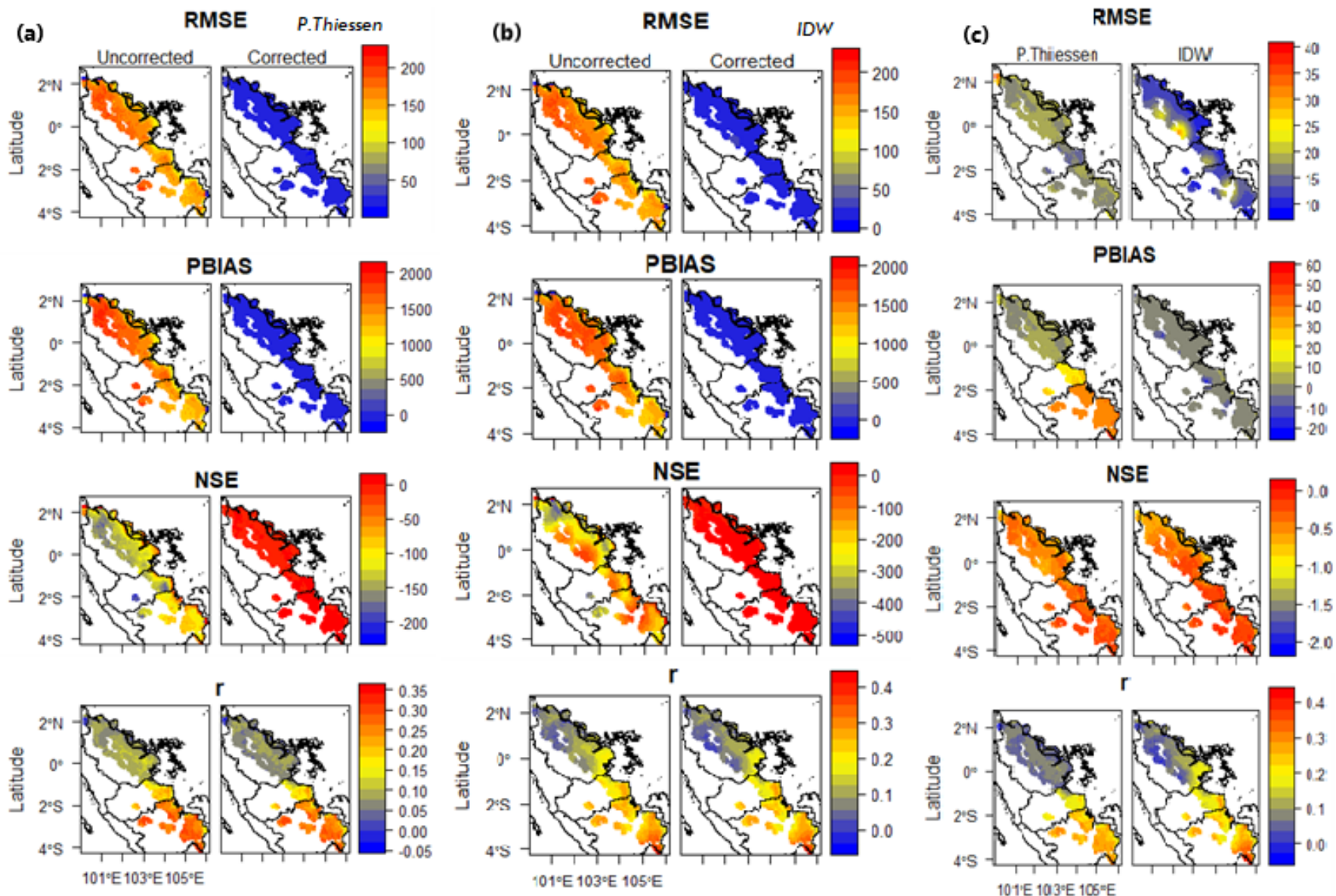

Figure 3. The result of the WRF model bias correction statistical test with observation data interpolated by (a) Polygon Thiessen method, (b) Inverse Distance Weighting (IDW) method, and (c) the comparison between those two methods. 
The performance comparison between the Polygon Thiessen and IDW methods (Figure 3c) shows that the error and bias of the IDW method are smaller than the Polygon Thiessen method. Likewise, the Pearson correlation indicator which shows that in Riau Province has a higher correlation in the IDW method. This can be expected to occur due to the IDW spatial interpolation process using a weighting system for station distance which makes the interpolation process better. Unlike the case with the Polygon Thiessen method, which divides the area into a few of areas and gives the same value to every pixel in one polygon area. This will certainly make the error bigger than IDW method.

The process of the WRF rainfall bias correction using two interpolation methods from the observational data showed a fairly good performance based on the statistical indicators that used (Figure 3c). PBIAS values for bias correction using the IDW method generally range between \pm 5 which indicates "very good" (Table 3). Likewise, the RMSE statistical indicator, in general shows an error less than $5 \mathrm{~mm}$. In contrast to the results shown by the Polygon Thiessen spatial interpolation method. PBIAS statistical indicator value is quite varied and high, even in the Sumatera Selatan province it reached more than 30 . According to Moriasi et al. (2015), these results are in the "unsatisfactory" category.

The process of bias correction on the WRF model output for rainfall parameters using observational data that interpolated using the IDW method, actually has been done before. Duethmann et al., (2013) conducted an evaluation of a WRF model with a spatial resolution of $12 \times 12 \mathrm{~km}$ to estimate rainfall in the Karadarya, Central Asia which was corrected using the IDW method for observational data interpolation. The bias that resulted on this process was in the range of $3 \%$ to $-5 \%$. These results indicate that the IDW method is "very good" in correcting the bias of the WRF model (Moriasi et al., 2015). The IDW method in the research of Duethmann et al., (2013) was used because it also takes into account topographic factors.

The rainfall forecast information from the output of the WRF model can be used for various purposes. The WRF model of rainfall information can be used directly as a continuous predictor of rainfall for the next
16 days, or it can also be integrated for further purposes. One of them is to predict the occurrence of floods or forest and land fires. Prediction of flood events using the WRF model output has been carried out with an RMSE streamflow of $0.18 \mathrm{~mm} / \mathrm{jam}$ (Sun et al. 2020). In addition to flood prediction, the output of the WRF model has also been applied to predict drought in forest and land fires. In Indonesia, the Meteorology, Climatology, and Geophysics Agency (BMKG) and the National Aeronautics and Space Agency (LAPAN) have applied rainfall information from the outputs of the WRF model to build models of potential forest and land fires. The drought model that used is the Fire Weather Index (FWI) by integrating rainfall information with air temperature, wind speed, and relative humidity. In addition, the Peatland and Mangrove Restoration Agency (BRGM) has collaborated with IPB University to build a peatland fire prediction model from the output of the WRF model using the modified Keetch - Byram Drought Index (mKBDI) developed by (Taufik and Narendratomo, 2011; Taufik et al., 2015).

\section{Limitation of Model}

There are several limitations to this study. Firstly, the WRF output is at $5 \mathrm{~km} \times 5 \mathrm{~km}$ resolution, and it was corrected and calibrated with limited point-based station data. The different resolution will usually result in generating large deviation output from the observed data. We performed bias correction procedure to decrease the error by using interpolated observed data. The use of IDW method for calibrating the rainfall of WRF was able to minimize the error (Figure 3). Our results show the error producing from bias correction was small $(<5 \%)$, and this proves that our approach is still robust to tackle with limited observed data.

Secondly, we performed a stepwise calibration to parameterize the WRF schemes. The calibration was chosen due to limitation on hardware resources and time constrain for computation process. Calibration of all WRF schemes and parameters in the same time will need robust high performance computing and it needs a more time for computation. The stepwise calibration was performed on step-by-step following the parameters that have the greatest influence (major factor) on the WRF output, in this case a rainfall.

Table 3. Model performance categories based on statistical indicators.

\begin{tabular}{lcc}
\hline \multicolumn{1}{c}{ Categories } & PBIAS & NSE \\
\hline Very good & $P B I A S< \pm 5$ & $N S E>0.8$ \\
\hline Good & $\pm 5 \leq P B I A S \leq \pm 10$ & $0.7 \leq N S E \leq 0.8$ \\
\hline Satisfactory & $\pm 10 \leq P B I A S \leq \pm 15$ & $0.5 \leq N S E \leq 0.7$ \\
\hline Unsatisfactory & $P B I A S \geq \pm 15$ & $N S E<0.5$ \\
\hline
\end{tabular}


Previous studies revealed that the cloud microphysics, cumulus cloud, and Planetary Boundary Layer (PBL) were the most influential schemes (Febri et al., 2016; Lamraoui et al., 2019; Y. Wang et al., 2020). The results of parameterization confirmed a relative small error (MAE $=7.91)$, and it led small bias in the WRF product for daily rainfall. Therefore, our approach is still acceptable to forecast daily rainfall in tropical region.

Third, in this research we calibrated the daily rainfall for 2019 only. Normally longer observation data, which represent normal, dry and wet years, are required for better results (Mehan et al., 2017). A short period of rainfall data for calibration may disregard the influence of climate extremes and variability on the dynamics of daily rainfall. In addition, global climate phenomena such as ENSO plays a major role on the dynamics of daily rainfall in maritime continent of Indonesia (Chang et al., 2020; Kurniadi et al., 2021; Mulyaqin, 2020). Longterm monitoring rainfall data particularly in peatland region will minimize the uncertainty in the calibrated parameters. Lastly, further work is necessary on longterm calibration of the WRF parameters especially using local observed data. The research has contributed to the society by providing a robust scientific foundation for further research, especially for development of fire danger rating system for peatland.

\section{CONCLUSIONS}

The research has important findings related to the use of Weather and Research Forecasting (WRF) in maritime continent. We found a set combination of WRF schemes that results in low error of the prediction. The combination was composed of the Eta scheme for cloud microphysical parameters, the GD scheme for cumulus cloud parameters, the MYJ scheme for PBL parameters, and the RRTM and New Goddard schemes for longwave and shortwave radiation parameters. The WRF output, i.e. rainfall, still needs bias correction process with observed data in the field. We found that Inverse Distance Weighting (IDW) interpolation of daily rainfall was a better representation for the bias correction as shown by statistical indicators used in the study.

\section{ACKNOWLEDGEMENT}

The authors thank to the Badan Restorasi Gambut (BRG) for providing and funding the research (contract number: SPKS.04/BRG/D4/06/2020). We also thank to World Resource Institute (WRI) for its assistance that facilitated field survey.

\section{REFERENCES}

Babaousmail, H., Hou, R., Ayugi, B., Gnitou, G.T., 2019. Evaluation of satellite-based precipitation estimates over Algeria during 1998-2016. Journal of Atmospheric and Solar-Terrestrial Physics 195, 105139. https://doi.org/10.1016/j.jastp.2019.105139

Berhanu, B., Seleshi, Y., Demisse, S.S., Melesse, A.M., 2016. Bias correction and characterization of climate forecast system re-analysis daily precipitation in Ethiopia using fuzzy overlay. Meteorological Applications 23, 230-243. https://doi.org/10.1002/met.1549

Chang, C.-P., Li, T., Yang, S., 2020. Seasonal Prediction of Boreal Winter Rainfall over the Western Maritime Continent during ENSO. Journal of Meteorological Research 34, 294-303. https://doi.org/10.1007/s13351-020-9181-Z

Chen, C., Li, Z., Song, Y., Duan, Z., Mo, K., Wang, Z., Chen, Q., 2020. Performance of Multiple Satellite Precipitation Estimates over a Typical Arid Mountainous Area of China: Spatiotemporal Patterns and Extremes. Journal of Hydrometeorology 21, 533-550. https://doi.org/10.1175/JHM-D-19-0167.1

Ciric, D., Nieto, R., Ramos, A.M., Drumond, A., Gimeno, L., 2017. Wet Spells and Associated Moisture Sources Anomalies across Danube River Basin. Water $\quad 9, \quad 615$ https://doi.org/10.3390/w9080615

Dai, A., 2006. Precipitation characteristics in eighteen coupled climate models. Journal of Climate 19, 4605-4630.

https://doi.org/10.1175/JCLI3884.1

Duethmann, D., Zimmer, J., Gafurov, A., Güntner, A., Kriegel, D., Merz, B., Vorogushyn, S., 2013. Evaluation of areal precipitation estimates based on downscaled reanalysis and station data by hydrological modelling. Hydrology and Earth System Sciences 17, 2415-2434. https://doi.org/10.5194/hess-17-2415-2013

Febri, D.H., Hidayat, R., Hanggoro, W., 2016. Sensitivity of WRF-EMS model to predict rainfall event on wet and dry seasons over West Sumatra. Procedia Environmental Sciences 33, 140-154. https://doi.org/10.1016/j.proenv.2016.03.065

Gunwani, P., Sati, A.P., Mohan, M., Gupta, M., 2021. Assessment of physical parameterization schemes in WRF over national capital region of India. Meteorol Atmos Phys 133, 399-418. https://doi.org/10.1007/s00703-020-00757-y

Harwell, M., 2019. A strategy for using bias and RMSE as outcomes in monte carlo studies in statistics. Journal of Modern Applied Statistical Methods 
17,

https://doi.org/10.22237/jmasm/1551907966

Jadmiko, S.D., Pacific (CCROM-SEAP), P.G.S. on A.C. of B.A.U. (IPB) C. for C.R. and O.M. in S.A. and, Murdiyarso, D., Lecturer on Geophysic and Meteorology Departemen, B.A.U. (IPB) C. for I.F.R. (CIFOR), Faqih, A., Center for Climate Risk and Opportunity Management in Southeast Asia and Pacific (CCROM-SEAP)Lecturer on Geophysic and Meteorology Departemen, B.A.U. (IPB), 2019. Koreksi Bias Luaran Model Iklim Regional untuk Analisis Kekeringan. Jurnal Tanah dan Iklim; Vol 41, No 1 (2017); 2535. https://doi.org/10.2017/jti.v41i1.5983

Kurniadi, A., Weller, E., Min, S.-K., Seong, M.-G., 2021. Independent ENSO and IOD impacts on rainfall extremes over Indonesia. International Journal of Climatology 41, 3640-3656. https://doi.org/10.1002/joc.7040

Lamraoui, F., Booth, J.F., Naud, C.M., Jensen, M.P., Johnson, K.L., 2019. The interaction between boundary layer and convection schemes in a WRF simulation of post cold frontal clouds over the ARM East North Atlantic site. Journal of Geophysical Research: Atmospheres 124, 4699-4721.

https://doi.org/10.1029/2018JD029370

Liu, H., Chen, J., Zhang, X.-C., Xu, C.-Y., Hui, Y., 2020. A Markov Chain-Based Bias Correction Method for Simulating the Temporal Sequence of Daily Precipitation. Atmosphere 11. https://doi.org/10.3390/atmos11010109

Mehan, S., Guo, T., Gitau, M.W., Flanagan, D.C., 2017. Comparative study of different stochastic weather generators for long-term climate data simulation. Climate 5, 26. https://doi.org/10.3390/cli5020026

Moriasi, D.N., W. Gitau, M., Pai, N., Daggupati, P., 2015. Hydrologic and Water Quality Models: Performance Measures and Evaluation Criteria. Transactions of the ASABE 58, 1763-1785. https://doi.org/10.13031/trans.58.10715

Mu, Z., Zhou, Y., Peng, L., He, Y., 2019. Numerical Rainfall Simulation of Different WRF Parameterization Schemes with Different Spatiotemporal Rainfall Evenness Levels in the Ili Region. Water 11, 2569. https://doi.org/10.3390/w11122569

Mulyaqin, T., 2020. The Impact of El Niño and La Nina on Fluctuation of Rice Production in Banten Province. Agromet 34, 34-41. https://doi.org/10.29244/j.agromet.34.1.34-41

Narulita, I., Ningrum, W., 2018. Extreme flood event analysis in Indonesia based on rainfall intensity and recharge capacity. IOP Conf. Ser.: Earth Environ. Sci. 118, 012045. https://doi.org/10.1088/17551315/118/1/012045

Nuijens, L., Siebesma, A.P., 2019. Boundary layer clouds and convection over subtropical oceans in our current and in a warmer climate. Current Climate Change Reports 5, 80-94. https://doi.org/10.1007/s40641-019-00126-x

Phogat, V., Skewes, M., Cox, J., Simunek, J., 2016. Statistical assessment of a numerical model simulating agro hydro-chemical processes in soil under drip fertigated mandarin tree. Irrig. Drain. Syst. Eng 5 . https://doi.org/10.4172/2168-9768.1000155

Piani, C., Weedon, G.P., Best, M., Gomes, S.M., Viterbo, P., Hagemann, S., Haerter, J.O., 2010. Statistical bias correction of global simulated daily precipitation and temperature for the application of hydrological models. Journal of Hydrology 395, 199-215. https://doi.org/10.1016/j.jhydrol.2010.10.024

Powers, J.G., Klemp, J.B., Skamarock, W.C., Davis, C.A., Dudhia, J., Gill, D.O., Coen, J.L., Gochis, D.J., Ahmadov, R., Peckham, S.E., 2017. The weather research and forecasting model: Overview, system efforts, and future directions. Bulletin of the American Meteorological Society 98, 17171737. https://doi.org/10.1175/BAMS-D-1500308.1

Rivera, J.A., Marianetti, G., Hinrichs, S., 2018. Validation of CHIRPS precipitation dataset along the Central Andes of Argentina. Atmospheric Research 213, 437-449. https://doi.org/10.1016/j.atmosres.2018.06.02 3

Sankey, S., 2018. Blueprint for wildland fire science in Canada (2019-2029).

Suciantini, R., Hidayat, R., 2006. Evaluasi prakiraan curah hujan BMG: studi kasus Kabupaten Indramayu. Agromet 20, 34-43. https://doi.org/10.29244/j.agromet.20.1.34-43

Sun, L., Wei, Y., Cai, H., Yan, J., Xiao, J., 2019. Improved Fast Adaptive IDW Interpolation Algorithm based on the Borehole Data Sample Characteristic and Its Application. Presented at the Journal of Physics: Conference Series, IOP Publishing, p. 012074. https://doi.org/ 10.1088/1742-6596/1284/1/012074

Surmaini, E., Susanti, E., Sarvina, Y., Syahputra, M.R., 2018. Development of Early Detection Method for Drought and Flood on Rice Paddy. Agromet 32, 81-92. https://doi.org/10.29244/j.agromet.32.2.81-92 
Tan, L., Shen, C.-C., Löwemark, L., Chawchai, S., Edwards, R.L., Cai, Y., Breitenbach, S.F.M., Cheng, H., Chou, Y.-C., Duerrast, H., Partin, J.W., Cai, W., Chabangborn, A., Gao, Y., Kwiecien, O., Wu, C.C., Shi, Z., Hsu, H.-H., Wohlfarth, B., 2019. Rainfall variations in central Indo-Pacific over the past 2,700 y. PNAS 116, 17201-17206. https://doi.org/10.1073/pnas.1903167116

Taufik, M., 2010. Analisis Perilaku Indeks Kekeringan di Wilayah Rentan Kebakaran, Sumatra Selatan. Agromet 24, 9-17. https://doi.org/10.29244/j.agromet.24.2.9-17

Taufik, M., Narendratomo, W., 2011. Analisis Indeks Bahaya Kebakaran Hutan untuk Wilayah Riau Indonesia Analiysis of Forest Fire Danger Index for Riau Region Indonesia. Agromet 25, 37-43. https://doi.org/10.29244/j.agromet.25.1.37-43

Taufik, M., Setiawan, B.I., Van Lanen, H.A.J., 2019. Increased fire hazard in human-modified wetlands in Southeast Asia. Ambio 48, 363-373. https://doi.org/10.1007/s13280-018-1082-3

Taufik, M., Torfs, P.J.J.F., Uijlenhoet, R., Jones, P.D., Murdiyarso, D., Van Lanen, H.A.J., 2017. Amplification of wildfire area burnt by hydrological drought in the humid tropics. Nature Climate Change 7, 428-431. https://doi.org/10.1038/nclimate3280

Taufik, Muh., Setiawan, B.I., van Lanen, H.A.J., 2015. Modification of a fire drought index for tropical wetland ecosystems by including water table depth. Agricultural and Forest Meteorology 203, $1-10$. https://doi.org/10.1016/j.agrformet.2014.12.00 6

Tegegne, G., Park, D.K., Kim, Y.-O., 2017. Comparison of hydrological models for the assessment of water resources in a data-scarce region, the Upper Blue Nile River Basin. Journal of Hydrology: Regional Studies 14, 49-66. https://doi.org/10.1016/j.ejrh.2017.10.002

Wang, D., Wang, P., Wang, C., Zhuang, S., Shi, J., 2020. A conformal prediction inspired approach for distribution regression with random Fourier features. Applied Soft Computing 97, 106807. https://doi.org/10.1016/j.asoc.2020.106807

Wang, Y., Feng, J., Luo, M., Wang, J., Qiu, Y., 2020. Uncertainties in simulating central Asia: Sensitivity to physical parameterizations using Weather Research and Forecasting model. International Journal of Climatology 40, 58135828. https://doi.org/10.1002/joc.6567

World Bank, 2016. The Cost of Fire: An Economic Analysis of Indonesia's 2015 Fire Crisis., Indonesia Sustainable Landscapes Knowledge Note: 1. The World Bank. https:/doi.org/ $10.1596 / 23840$

Yáñez-Morroni, G., Gironás, J., Caneo, M., Delgado, R., Garreaud, R., 2018. Using the Weather Research and Forecasting (WRF) model for precipitation forecasting in an Andean region with complex topography. Atmosphere 9, 304. https://doi.org/10.3390/atmos9080304

Zheng, X., Klein, S., Ma, H., Caldwell, P., Larson, V., Gettelman, A., Bogenschutz, P., 2017. A cloudy planetary boundary layer oscillation arising from the coupling of turbulence with precipitation in climate simulations. Journal of Advances in Modeling Earth Systems 9, 1973 1993. https://doi.org/10.1002/2017MS000993 